\section{Repetition versus imagery instructions in the short- and long-term retention of paired-assoclates'}

\section{J. A. SCHNORR and R. C. ATKIVSON, Stanford University, Stanford, Calif. 94305}

Eighteen Ss leamed three lists of 32 paired associates by the study-test method. Half of the items in each list were studied by' repetition, and the other half by imagery. Imagery study resulted in better recall than did repetition study. Informing $S$ at the time of test of the study method used for a given paired associate enhanced recall of items from List 1 , but did not influence recall on Lists 2 and 3. In addition, initial recall performance was poorer on List I than on the other lists, although List 1 items were better retained over a l-week interval The results suggest that storage processes employed by $S$ are dependent upon test experience.

Using a between-Ss design, Paivio \& Yuille (1967) and Yuille \& Paivio (1968) demonstrated that imagery was superior to repetition in the recall of paired associates. One possible implication of this result is that different memory stores are associated with the two study methods. If this is the case, then cues that direct $S$ to the appropriate memory store at the time of test should aid recall (Atkinson \& Shiffrin, 1968). The present study tested this hypothesis by manipulating study method as a within-Ss variable, and either cueing or not cueing $S$ during test regarding the method by which each stimulus-response pair was studied. The effects of cue and study method on recall were measured at two different retention intervals.

\section{METHOD}

Three lists of 32 noun pairs were constructed using words selected from the Howes (1966) count of spoken English. Only easily imaginal nouns were used so that pairs could be studied by imagery without difficulty. 2 The pairs were determined randomly, with the restriction that no pair involved words that were obvious associates. Pairs were typed on white $3 \times 5$ cards and presented manually by $\mathrm{E}$.

The Ss were 18 introductory psychology students at Stanford University whose participation fulfilled a course requirement. Each $S$ sat at a table upon which were cards labelled "Imagery" (I) and "Repetition" (R). For each word pair placed by the "I" marker (I items), S's task was to create a mental image in which the two words were interacting and to describe the image to $E$.
For pairs placed by the " $R$ " marker ( $R$ items), $S$ was instructed to repeat the pair slowly four times, and to refrain from using either verbal or imaginal mediation. Eight seconds were given for the study of each word pair, and the study method (I or R) was alternated from one block of four word pairs to the next. Subsets of six Ss received a different presentation ordering of the three lists, and counterbalancing procedures assured that individual items were studied by both methods.

A recall test immediately followed the study of each list. At the onset of each test trial, $E$ held the stimulus card, face down, either behind one of the "I" or " $R$ " markers noncued stimuli was random with the restriction that both conditions occurred equally of ten. After stimulus presentation, $S$ had $8 \mathrm{sec}$ to respond, and no feedback was given as to the correct response. Study and test orderings of the items differed so that it was not possible to deduce from the test order what study methods had been used for noncued stimuli. After testing was completed, S was requested to return 1 week later to participate in a "related experiment." Upon return, S was retested for retention of all three lists. For each study method, the stimuli cued in retest were half of the stimuli cued and half not cued in the original test. (cued condition), or behind an unmarked card (no cue). The ordering of cued and

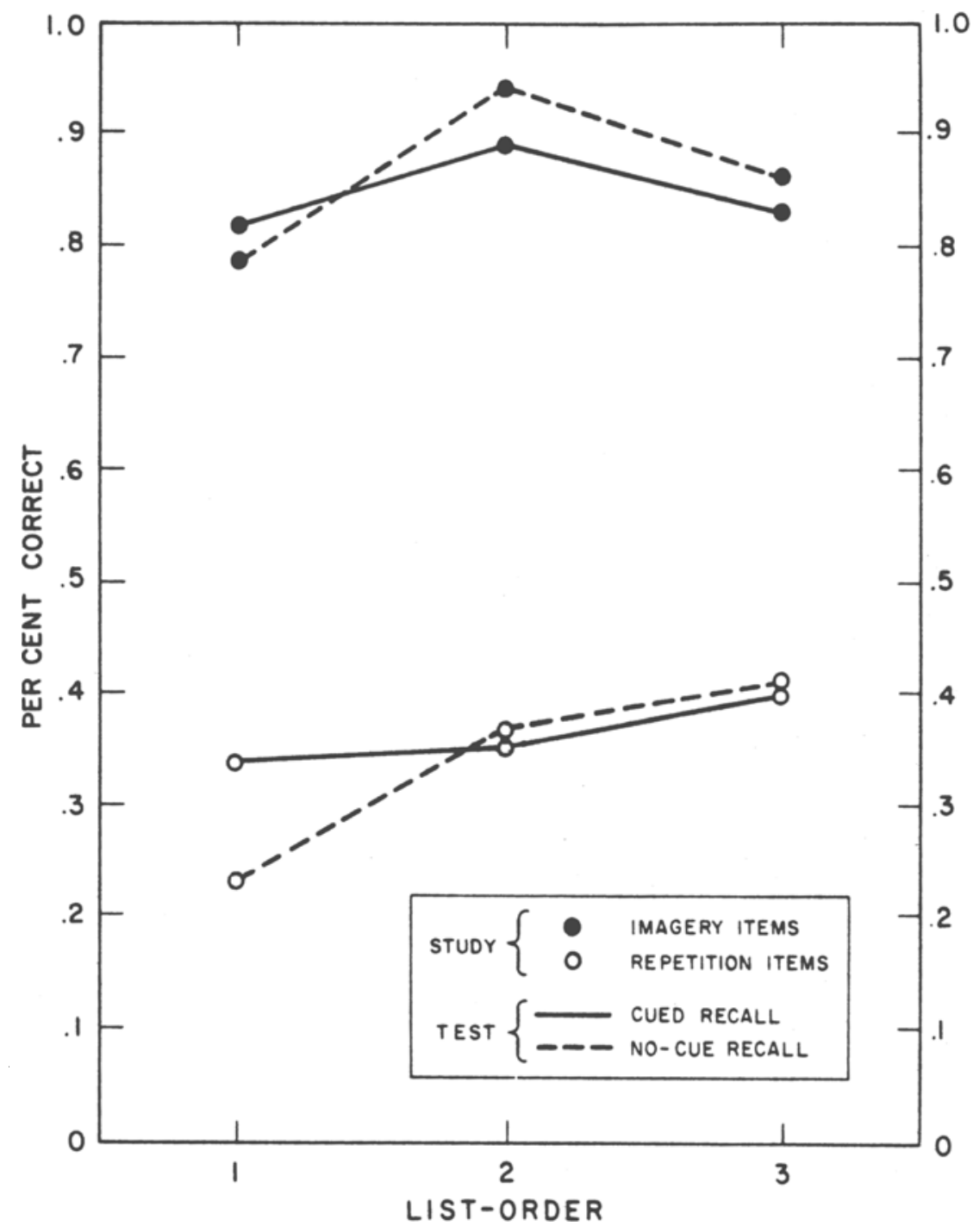

Fig. 1. Per cent correct recall on the initial test as a function of study method, cue condition, and list. 
RESULTS

Figure 1 presents the probability of correct recall on the initial test as a function of study method, cue, and lists. Imagery rather than repetition resulted in superior recall $[F(1,19)=181.4, p<.001]$. Recall improved over lists $[F(2,34)=5.83$, $p<.01]$, although there was no difference between recall performance on Lists 2 and 3 $(F<1)$. Cueing enhanced recall of List 1 items $[F(1,17)=7.62, p<.025]$, but the direction of the effect was slightly reversed thereafter, resulting in a Cue Condition by List interaction $[F(2,34)=3.61, p<.05]$. No other sources of variance were significant.

Since $97.6 \%$ of the correct responses in the retest were also correct in the initial test, the measure of retention used for analysis was the proportion of items correctly recalled in the initial test that were correctly recalled 1 week later. Preliminary analyses revealed that cue condition in retest did not influence recall $(F<1)$, and the retest scores were accordingly pooled over cue condition in order to provide more reliable data. Table 1 presents the retention percent. ages, averaged over $\mathrm{Ss}$, for each combination of study method and lists. Retention was better for I items than for $R$ items $[F(1,17)=10.46, p<.005]$. For both study methods, List 1 retention was better than retention of Lists 2 and 3 , although this difference was significant only for litems $[F(2,34)=5.15, \mathrm{p}<.025]$.

\section{DISCUSSION}

The result that noun pairs studied by imagery are better learned and better remembered than items studied by repetition replicates the findings of previous research in which study method was varied between Ss (Paivio \& Yuille, 1967; Yuille \& Paivio, 1968). Since the present experiment manipulated study method within $\mathrm{Ss}$, it is apparent that $S s$ are able to employ two different encoding strategies concurrently during the presentation of a single list.

The hypothesis that different memory stores are associated with the two study methods is supported by the finding that knowledge of study method aided recall of List 1 items. The enhanced recall implies that retrieval-relevant information increased the probability that $S$ would search the appropriate memory store during test, thereby decreasing interference effects between I items and R items. The absence of a cue effect for Lists 2 and 3 suggests that stimulus information alone was employed during recall of these lists. Since a refinement in storage processes could have resulted in stimulus information alone directing $S$ to the appropriate memory store during test, the lack of a cue effect for Lists 2 and 3 is not necessarily in opposition to a dual-storage hypothesis.
Table I

Probability of Correct Retest Recall Given Correct Recall on the Initial Test

\begin{tabular}{lccc}
\hline & \multicolumn{3}{c}{ List Order } \\
\cline { 2 - 5 } Study Method & 1 & 2 & 3 \\
\hline Imagery & .453 & .341 & .352 \\
Repetition & .311 & .239 & .247 \\
\hline
\end{tabular}

The surprising result was that list-order effects for initial and delayed recall scores were opposite in direction. Relative to performance on Lists 2 and 3, initial recall was poorer; however, recall a week later was superior for List 1 items. This seemingly anomalous relationship implies that the storage process operative during List 1 study differed from that employed during the study of subsequent lists. One possible hypothesis is as follows: Prior to test experience $S$ was not aware of the studytest interval and, to insure a high level of performance, studied List 1 items so that they would be remembered over very long retention intervals. After the test on List 1, this storage process (SP-1) was replaced by one more appropriate to the study-test interval actually employed on the first day (SP-2). In order to account for the data, it must be assumed that SP-1 produced more interitem interference than did SP-2, with the result that: (1) initial recall performance was lower for List 1 items than for items in Lists 2 and 3, and (2) providing retrievalrelevant information during List 1 test enhanced recall.

\section{REFERENCES}

ATKINSON, R. C., \& SHIFFRIN, R. M. Human memory: A porposed system and its control processes. In K. W. Spence and J. T. Spence (Eds.), The psychology of learming and motivation: Advances in research and theory. Vol. 2. New York: Academic Press, 1968. Pp. 89-195.

HOWES, D. A word count of spoken English. Journal of Verbal Leaming \& Verbal Behavior, $1966,5,572-604$.

PAIVIO, A., \& YUILLE, J. C. Mediation instructions and word attributes in pairedassociate learning. Psychonomic Science, 1967, 8, 65-66.

PAIVIO, A., YUILLE, J. C., \& MADIGAN, S. A. Concreteness, imagery, and meaningfulness values for 925 nouns. Journal of Experimental Psychology, 1968, 76, No. 1, Part 2, 1-25.

YUILLE, J. C., \& PAIVIO, A. Imagery and verbal mediation instructions in paired-associate learning. Journal of Experimental Psy chology, 1968, $78,436-441$.

\section{NOTES}

1. This research was conducted during the senior author's tenure as a Public Health Service Postdoctoral Fellow at Stanford University.

2. While the selection criterion was subjective, the words used in this study that are in the Paivio, Yuille, \& Madigan (1968) norms $(N=54)$ have concreteness and imagery values greater than 6.0 .

\section{Facilitation of paired-assoclate learning by language context}

MARK WIND and MICHAEL DAVIDSON, University of Rochester, Rochester, N.Y. 14627

Subjects learned associations between English words and unfamiliar items (CVC syllables). Control Ss used a traditional paired-associate method; experimental $S$ s received each pair in a sentence context appropriate for the English word. Learning was facilitated by the language context.

The learning of a second-language vocabulary may be viewed in part as paired-associate learning of first- and second-language synonyms (e.g., tree-Baum in English-German vocabulary). Mediational theories of meaning (Osgood, 1953) suggest that such learning could be facilitated by evoking a context of inplicit meaning responses for the familiar word when the pair is presented. One appropriate method might be to provide a sentence context for the familiar word during training, as in "The $B A U M$ had beautiful autumn leaves (TREE)." Naive association theory, on the other hand, might suggest that the additional context items would interfere with the association to be formed. Our experimental question is whether paired. associate learning between an English word and an unfamiliar item is enhanced by providing a meaningful-sentence context for the English word.

\section{SUBJECTS}

The Ss were 64 students in an introductory psychology course at the University of Rochester. Participation in experiments was a course requirement. 